\title{
Barth Handbuch
}

\author{
Hrsg. v. Michael Beintker
}

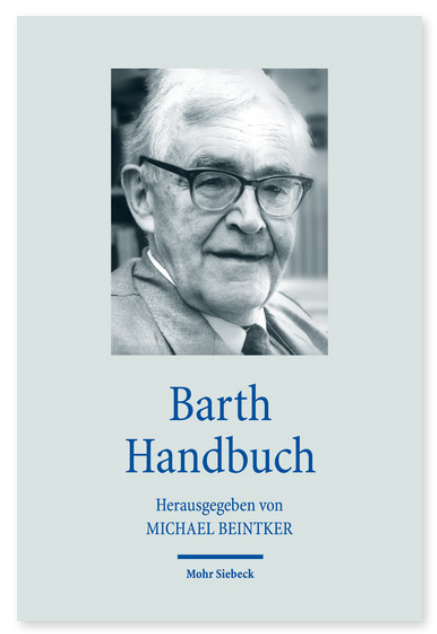

2016. XVIII, 538 Seiten. HdTh

SBN 978-3-16-154351-7

DOI 10.1628/978-3-16-154351-7

eBook PDF 149,00€

ISBN 978-3-16-150076-3

fadengeheftete Broschur 49,00€

ISBN 978-3-16-150077-0

Leinen $149,00 €$
Karl Barth (1886-1968) war einer der großen prägenden Theologen des 20. Jahrhunderts. Mit seinen theologischen Arbeiten erreichte er weltweiten Einfluss. Nach dem Ersten Weltkrieg formierte sich mit der von ihm inspirierten »dialektischen Theologie« die damals bedeutendste Aufbruchsbewegung der evangelischen Theologie. Sein Denken erlangte in den dramatischen Auseinandersetzungen zwischen Kirche und Nationalsozialismus kirchenpolitische Orientierungskraft von historischer Dimension. Als theologischer Lehrer der evangelischen Kirche hat Barth in seiner Kirchlichen Dogmatik zentrale Grundeinsichten der reformatorischen Theologie aufgenommen und weiterentwickelt. Er muss als ein problemsensibler theologischer Autor gelesen werden, der sich den Herausforderungen der Moderne nicht verweigerte, sondern sich in einem häufig unterschätzten Ausmaß auf ihre Herausforderungen eingelassen hat.

In der Reihe der Theologen Handbücher bietet das Karl Barth Handbuch übersichtliche und instruktive Zugänge zur Biografie, zur Werk- und Wirkungsgeschichte und zu den profilbildenden theologischen Entscheidungen und Themen im Denken dieses großen Theologen. Es wendet sich in gleicher Weise an allgemein Interessierte und an Fachleute. Die einzelnen Artikel können sowohl als Hinführung als auch als Bündelung und Fokussierung gelesen werden. Das Barth Handbuch ist ein unentbehrliches Hilfsmittel für jeden, der sich mit dem Werk Karl Barths und seiner Interpretation beschäftigt.

Inhaltsübersicht

\section{A. Orientierung}

I. Peter Zocher: Ausgaben

II. Peter Zocher: Hilfsmittel

III. Michael Beintker: Barth-Forschung heute

\section{B. Person}

I. Voraussetzungen

Eberhard Busch: Elternhaus und Familie - Eberhard Busch: Lehrjahre - Eberhard Busch: Pfarrer - Hartmut Genest: Exeget und Prediger - Rudolf Smend: Akademischer Lehrer - Georg Plasger: Luther und Calvin - Friedrich Lohmann: Kant, Kierkegaard und der Neukantianismus - Hinrich Stoevesandt: Eduard Thurneysen - Hinrich Stoevesandt: Charlotte von Kirschbaum

II. Beziehungen

Georg Pfleiderer: Barth und die liberale Theologie - Bruce L. McCormack: Barth und Schleiermacher - Christian Link: Barth und der religiöse Sozialismus - Gerhard Sauter: Barth und Blumhardt - Eberhard Busch: Barth und der Pietismus - Wilhelm Hüffmeier: Barth und Gogarten - Frank Jehle: Barth und Brunner - Konrad Hammann: Barth und Bultmann - Arie Molendijk: Barth und Scholz - Michael Moxter: Barth und Tillich - Christiane Tietz: Barth und Bonhoeffer - Detlev Schneider: Barth und Maury - Martin Hailer: Barth und Miskotte - Ernstpeter Maurer: Barth und das Luthertum - Matthias Freudenberg: Barth und die Reformierten - Amy Marga: Barth und der Katholizismus - Thomas Herwig: Barth und die Ökumene - Eberhard Busch: Barth und die Juden - Martin Greschat: Barth und die Politik

III. Prägungen

Michael Trowitzsch: Hermeneutik - Ernstpeter Maurer: Sprache bei Barth - Eberhard Busch: Musik - Michael Beintker: Politik

C. Werk

Stadien

Georg Pfleiderer: Liberale Phase - Cornelis van der Kooi: Erster Römerbrief - Cornelis van der Kooi: Zweiter Römerbrief Michael Beintker: Dialektische Theologie - Michael Beintker: Der Dialektiker als Dogmatiker - Michael Beintker: Fides quaerens intellectum - Michael Hüttenhoff: Theologische Existenz heute - Wolf Krötke: Erwählungslehre - Bruce L. McCormack: Christonomie - Michael Beintker: Resümee: Periodisierung des Barthschen Denkens

II. Gattungen

Hartmut Genest: Predigten - Michael Trowitzsch: Exegetische Arbeiten - Bruce L. McCormack: Dogmatische Werke - Torsten Meireis: Arbeiten zur Ethik - Dietrich Korsch: Theologiegeschichte - Gerhard Sauter: Vorlesungen - Gerhard Sauter: Vorträge - Matthias Freudenberg: Gespräche - Peter Zocher: Briefe

III. Themen

Dietrich Korsch: Aufgabe der Theologie - Cornelis van der Kooi: Religion und Glaube - Michael Weinrich: Trinität - Martin Hailer: Offenbarung - Wolf Krötke: Gottes Souveränität und Menschlichkeit - Georg Plasger: Jesus Christus - Michael Weinrich: Bund - J. Christine Janowski: Gnadenwahl - Christian Link: Schöpfung und Vorsehung - Christian Link: Anthropologie - Wolf Krötke: Sünde und Nichtiges - Michael Weinrich: Architektur der Versöhnungslehre - Michael Beintker: Rechtfertigung und Heiligung - André Demut: Evangelium und Gesetz - Hans-Peter Großhans: Kirche - Michae/ Weinrich: Sakramente - Eberhard Busch: Taufe - Martin Hailer: Hoffnung für die Welt - Martin Hailer: Christliches Leben - HansRichard Reuter: Ethik des Politischen

IV. Profile

Michael Trowitzsch: Theologie als fröhliche Wissenschaft - Bent Flemming Nielsen: Theologie als kritische Wissenschaft - 


\section{Wirkung und Rezeption}

I. Dietrich Korsch: In den 1920er Jahren

II. Martin Greschat: In der Auseinandersetzung mit dem Nationalsozialismus

III. Peter Zocher: In der Kriegs- und Nachkriegszeit

IV. Ulrich H. J. Körtner: In der Blütezeit der Theologie Bultmanns

V. Stefan Holtmann: In den Paradigmenwechseln der 1970er Jahre

VI. Cornelis van der Kooi: Am Ende des 20. Jahrhunderts

VII. Michael Beintker: Am Beginn des 21. Jahrhunderts

Alexander Dölecke: Biographische Zeittafel

Michael Beintker Geboren 1947; 1965-70 Studium der Theologie in Jena und Halle/Saale; 1972 Promotion; 1984 Habilitation; 1972-85 Wissenschaftlicher Mitarbeiter an der Theologischen Fakultät der Martin-Luther-Universität Halle-Wittenberg, danach dort Dozent; 1990 Berufung auf die Professur für Systematische Theologie in Halle; 1992-2015 Professor für Systematische Theologie und Direktor des Seminars für Reformierte Theologie an der Universität Münster; seit 2015 emeritiert.

Jetzt bestellen:

https://mohrsiebeck.com/buch/barth-handbuch-9783161543517?no_cache=1

order@mohrsiebeck.com

Telefon: $+49(0) 7071-923-17$

Telefax: $+49(0) 7071-51104$ 